\title{
New Capability for Ozone Dial Profiling Measurements in the TROPOSPHERE AND LOWER STRATOSPHERE FROM AIRCRAFT
}

\author{
Johnathan Hair ${ }^{l}$, Chris Hostetler ${ }^{l}$, Anthony Cook $^{l}$, David Harper ${ }^{l}$, Anthony Notari ${ }^{l}$, Marta Fenn ${ }^{2}$, \\ Mike Newchurch ${ }^{3}$, Lihua Wang ${ }^{3}$, Shi Kuang ${ }^{3}$, Travis Knepp ${ }^{2}$, Sharon Burton ${ }^{l}$, Richard Ferrare ${ }^{l}$, \\ Carolyn Butler ${ }^{2}$, Jim Collins $^{2}$, Amin Nehrir ${ }^{1}$ \\ ${ }^{1}$ NASA Langley Research Center Hampton, VA USA: Johnathan.W.Hair@nasa.gov \\ ${ }^{2}$ Science Systems and Applications, Inc., Hampton, VA USA, ${ }^{3}$ University of Alabama in Huntsville, \\ Huntsville, AL USA
}

\begin{abstract}
Recently, we successfully demonstrated a new compact and robust ozone DIAL lidar for smaller aircraft such as the NASA B200 and the ER-2 high-altitude aircraft. This is the first NASA airborne lidar to incorporate advanced solid-state lasers to produce the required power at the required ultraviolet wavelengths, and is compact and robust enough to operate nearly autonomously on the high-altitude ER-2 aircraft. This technology development resulted in the first new NASA airborne ozone DIAL instrument in more than 15 years. The combined ozone, aerosol, and clouds measurements provide valuable information on the chemistry, radiation, and dynamics of the atmosphere. In particular, from the ER-2 it offers a unique capability to study the upper troposphere and lower stratosphere.
\end{abstract}

\section{INTRODUCTION}

NASA Langley's current airborne lidar Ozone and Aerosol Lidar instrument provide profiles of ozone via the Differential Absorption Lidar (DIAL) technique and aerosol and cloud optical properties via the High Spectral Resolution Lidar (HSRL) technique. This lidar has been a much relied-upon facility-class instrument for deployment on the larger aircraft platforms (i.e., DC-8) over the last three decades, having been deployed on 33 major field experiments focused on investigation of regional- and global-scale processes within tropospheric and stratospheric, satellite validation, and model assessments [1]. Ozone lidar measurements continue to be a requirement on many NASA-sponsored airborne process studies and validation campaigns such as the recent and successful SEAC4RS and KORUS campaigns and will be important for future satellite (e.g. TEMPO and SAGE-ISS) validation campaigns.
This abstract provides a technical overview of major subsystems of this new instrument, an overview of potential new investigations, and highlight a few examples of ozone and aerosol profiles acquired during flights in January 2016 and April 2016 from the B200 and ER-2 aircraft platforms, respectively. In addition, the ozone profiles measured by the lidar are compared with profiles from ozonesondes and ground-based TOLNet ozone lidar systems.

\section{METHODOLOGY}

This new system is designed to combine aerosol/cloud and the trace gas ozone measurements into a single integrated instrument. The driving requirement was to develop a lidar system that is much smaller, lighter, and uses less power compared to previous generations. In addition, to fly on the ER-2 aircraft the system had to operate autonomously or with very limited remote control.

\subsection{Laser Subsystem}

A critical development was the laser systems. The laser system consists of a Nd:YAG pump laser built by Fibertek Inc. and a nonlinear optics module (NLO) that was built by IIT Industries with modifications by NASA LaRC and Welch Mechanical Designs, LLC. The NLO consists of two Optical Parametric Oscillators (OPOs) and two crystals for Sum Frequency Generation (SFG). The pump laser is a seeded single frequency $1064 \mathrm{~nm}$ laser that has a single oscillator and a single preamplifier. The light from the pump laser is then split to two amplifier paths. This results in two output beams with $100 \mathrm{~mJ}$ per pulse at $200 \mathrm{~Hz}(20 \mathrm{~W})$ in each output. One of the amplifier outputs is frequency doubled (SHG) and then frequency tripled (THG). The other amplifier output is used to pump the two OPOs that generate $1608 \mathrm{~nm}$ and $1945 \mathrm{~nm}$ which are then 
mixed with $355 \mathrm{~nm}$ in two SFG crystals to produce the $290 \mathrm{~nm}$ and $300 \mathrm{~nm}$ ozone DIAL wavelengths.

Nd:YAG Laser (bottom in Figure 1)

(Fibertek Inc.)

- $40 \mathrm{~W}$ laser, $200 \mathrm{~Hz}$ pulse rate, seeded single frequency

- 20W leg to pump dual Optical Parametric Oscillators (OPO)

- $20 \mathrm{~W}$ leg to generate $355 \mathrm{~nm}, 532 \mathrm{~nm}, 1064 \mathrm{~nm}$

- Aerosol and cloud measurements are conducted at $355,532,1064 \mathrm{~nm}$

Nonlinear Optics Module (top in Figure 1) (ITT Industries, Welch Mechanical Designs, NASA LaRC)

- 1W @ 290nm and 0.5W @ 300 nm, 200Hz

- Dual OPOs: $1608 \mathrm{~nm}$ and 1945nm

- Sum frequency generation (SFG): mix OPO and $355 \mathrm{~nm}$ to generate Ozone DIAL wavelengths

Summary of Transmitted Wavelengths

- Transmit single frequency 3.6W @ 1064nm, 2.5W@532nm, and 3.5W @355nm wavelengths required for HSRL measurements.

- Transmit1W@290nm and 0.5W @300nm

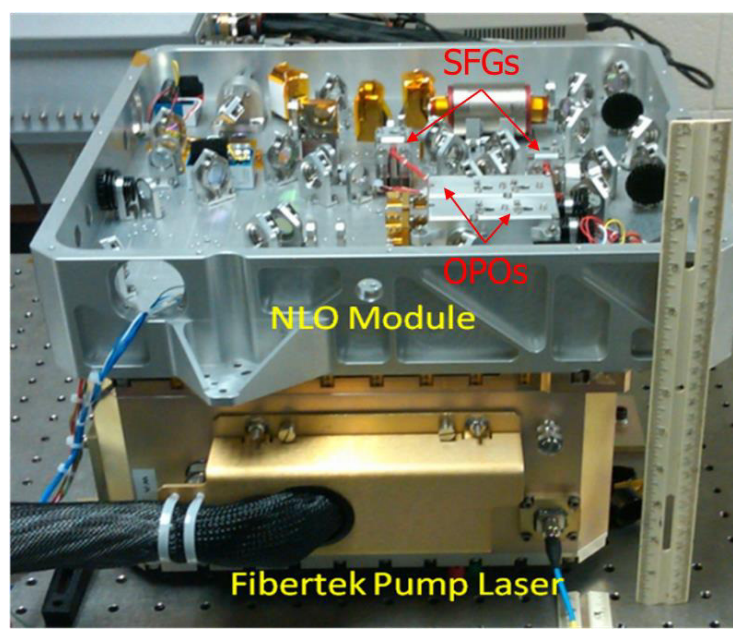

Figure 1. Picture of the Nd:YAG laser (bottom) and the nonlinear optics module (top) that contain dual OPOs and SFG mixers.

\subsection{Receiver Subsystem}

The receiver consists of multiple channels for the aerosol/cloud and ozone measurements. The system incorporates the HSRL technique at both $532 \mathrm{~nm}$ and $355 \mathrm{~nm}$ using an iodine vapor filter and Michelson Interferometer, respectively. The $1064 \mathrm{~nm}$ channels are detected using the standard backscatter approach with calibration from the $532 \mathrm{~nm}$ channel. The $532 \mathrm{~nm}$ and $1064 \mathrm{~nm}$ retrievals are implemented similar to Hair et al. (2010) [2]. The system also measures the linear depolarization ratio for all three wavelengths [3]. The system has flown on multiple campaigns with the aerosol/cloud measurement channels since 2012. Here we report additional channels that are included in the system to enable ozone profiling through the Differential Absorption Lidar (DIAL) technique focused on measurements in the lower stratosphere and troposphere. These ozone wavelengths are transmitted simultaneously and are split in the receiver with a dichroic filter where each channel has $1 \mathrm{~nm}$ wide interference filter before the photomultiplier detectors.

\subsection{Overall System Design}

As noted above, a main objective was to reduce the overall size, weight, and power requirements of this new instrument compared to the current airborne ozone DIAL system that Langley has flown over the past 3 decades. This was accomplished mainly by the laser system approach and design along with the supporting custom electronics and chillers. In addition, considerable effort was put forth in the design of the receiver and instrument structure. The telescope incorporates a $40 \mathrm{~cm}$ diameter all-metal telescope and a dual-sided aft-optics breadboard. A comparison of the two system sizes is provided in Figure 2 and Table 2. The new system is configured to view downward (e.g. from ER-2) in contrast to the current DIAL system, which simultaneously views in the nadir and zenith directions (e.g. from DC-8).

Table 2. Comparison of size, weight, and power of the new system compared to the current system.

\begin{tabular}{|l|c|c|c|}
\hline & $\begin{array}{c}\text { UV } \\
\text { DIAL }\end{array}$ & $\begin{array}{c}\text { HSRL/ } \\
\text { DIAL }\end{array}$ & Change \\
\hline Volume(m³) & 3.7 & 0.34 & $11 x$ \\
\hline Weight(kg) & 907 & 135 & $7 \mathrm{x}$ \\
\hline Power(kW) & 9.75 & 1.7 & $6 \mathrm{x}$ \\
\hline
\end{tabular}




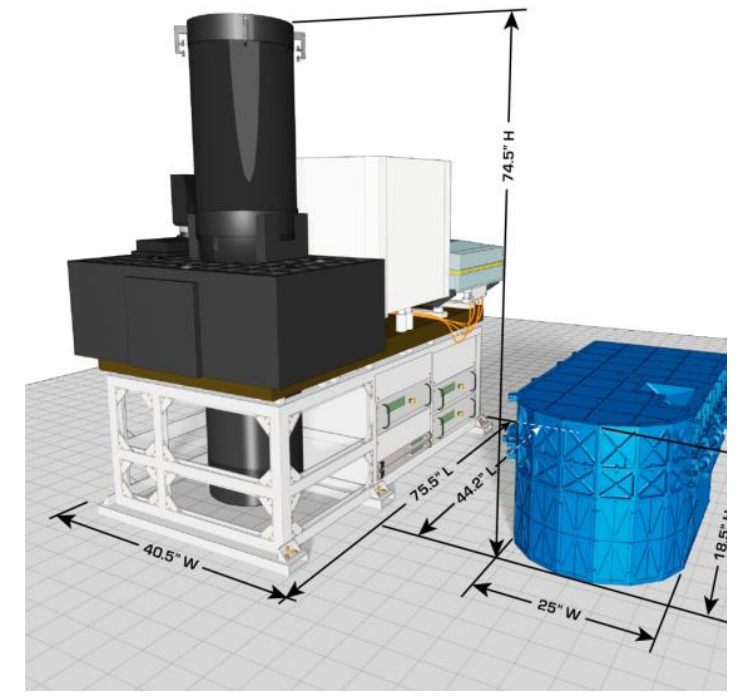

Figure 2. Comparison of the size of the current (left) and the new (right) lidar transceivers.

\section{RESULTS}

Two series of test flights were conducted on the NASA B200 aircraft from Hampton, VA in January 2016 (5 flights) and on the ER-2 aircraft from Palmdale CA in April 2016 (7 flights). The flights conducted from the B200 focused on evaluating the measurement performance of the ozone measurement and included overpasses of three TOLNet ground-based lidar systems: LMOL in Hampton VA, TropOz in Greenbelt MD, and $\mathrm{RO}_{3}$ QET in Huntsville AL. Ozonesondes were launched at three locations (Hampton and Wallops Island VA and Huntsville AL) during overpasses of the B200 aircraft. Airborne lidar measurements from 25 January 2016 are compared to measurements from an ozonesonde launched in Hampton, VA (Figure 3) showing a typical ozone profile. The lidar profile (green) compared favorably with the sonde profile (black) with a maximum and minimum difference of $-13.5 \%$ and $10 \%$ and the mean standard deviation over the profile of $5.9 \%$. There was no mean bias over the profile for this particular sonde comparison. The average of all six ozonesonde comparisons resulted in a mean profile bias of $-1.2 \%$ and a mean profile standard deviation of $5.7 \%$.

The seven ER-2 flights focused mainly on operational performance of the instrument,
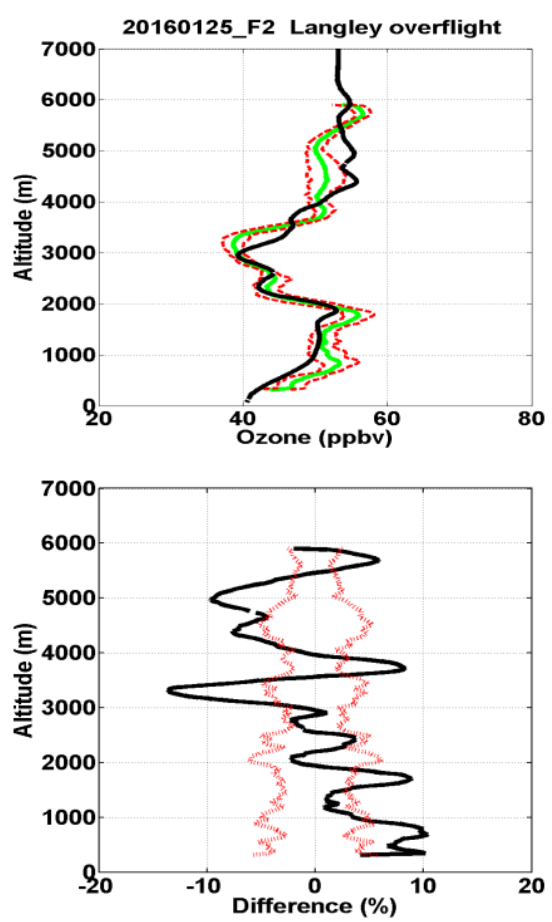

Figure 3. Comparison of lidar and ozonesonde profiles measured 25 January 2016. The top plot shows the sonde (black) and the lidar (green) ozone mixing ratio. The red lines show the ozone standard deviation over the measured interval for the lidar. The bottom plot shows the difference (black) in the ozone profile and the standard deviation over the averaging interval of the lidar.

including flying at altitudes up to $\sim 20 \mathrm{~km}$ to assess the quality of the measurements within the lower stratosphere and near the tropopause. A flight conducted on 13 April 2016 flew from Southern California (lat $=34.6 \mathrm{~N})$ south to $15 \mathrm{~N}$ over the Pacific Ocean. The ozone curtain measured during the transit to this southern point is shown in Figure 4. The profiles extended down to the cloud tops near $2 \mathrm{~km}$ altitude after the ER-2 descended to $18 \mathrm{~km}$. The unique capability of the lidar clearly observes the large-scale features in the ozone horizontal and vertical distribution. The lidar ozone profiles revealed a large tropopause fold that extended nearly over the entire flight track. The small aerosol layers, shown in Figure 4 (bottom) correlated with the increased ozone in the mid-troposphere. A sudden decrease in ozone is observed while crossing the Inter-Tropical Convergence Zone (ITCZ). The data also highlights the transport of lower ozone due to the 
large-scale dynamics related to convection in the tropics and the Brewer-Dobson circulation.

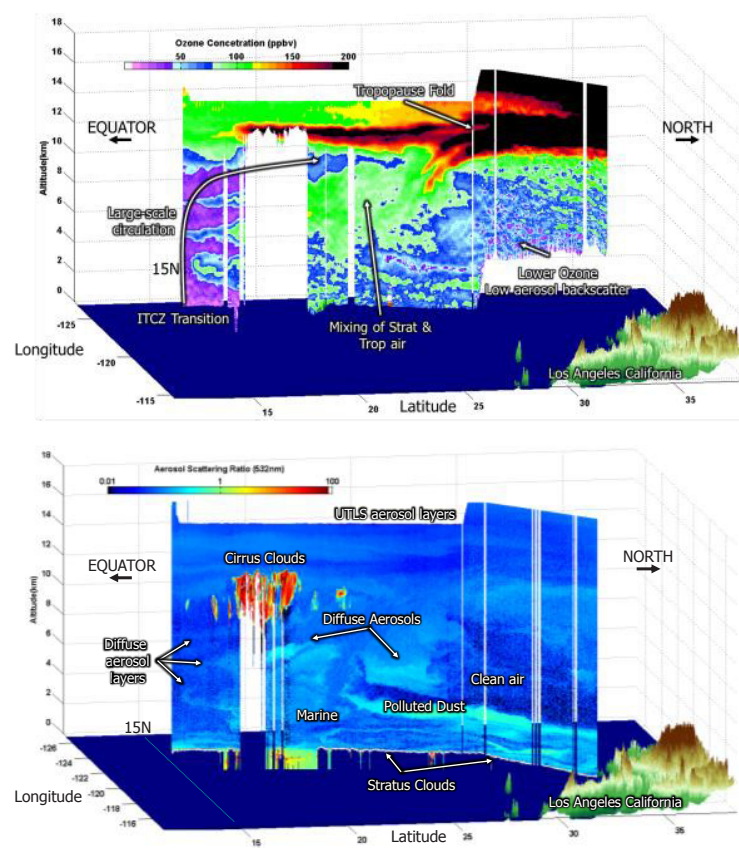

Figure 4. Ozone distribution (top) and the $532 \mathrm{~nm}$ aerosol to molecular backscatter ratio (bottom) measured on flight from 13 April 2016.

\section{CONCLUSIONS}

The first NASA airborne ozone lidar developed to fly on both small aircraft (B-200) and highaltitude aircraft (ER-2) has successfully demonstrated. The instrument performed well on all the 12 flights conducted to date and demonstrated reliable and hands-off performance of dual OPO-based UV lasers at $290 \mathrm{~nm}$ and $300 \mathrm{~nm}$. These flights provided the first opportunity to assess the measurement performance. The lidar ozone profiles compared well with profiles from coincident ozonesonde launches to within $1.2 \%$ with a variation of $5.7 \%$ on average. The airborne lidar profiles also compared well with profiles from the groundbased TOLNet DIAL lidar at University of Alabama in Huntsville. Comparisons to the other TOLNet sites have yet to be analyzed. The flights from the ER-2 demonstrated the lidar performance in a near autonomous operation and provided unique profiles of the lower stratosphere and upper troposphere ozone and aerosol distributions. In addition, current plans are to implement a recently developed Fibertek Inc. OPO laser system that operates at 304 and $316 \mathrm{~nm}$. This laser system is currently being integrated with the same pump laser described above and will enable profiling from $20 \mathrm{~km}$ to the surface at all latitudes.

\section{ACKNOWLEDGEMENTS}

This technology development supported through the NASA Earth Science Technology Office (ESTO) and the NASA Science Mission Directorate (SMD), Research and Development Program.

\section{References}

[1] Browell, E. V., S. Ismail, and W. B. Grant. "Differential absorption lidar (DIAL) measurements from air and space." Applied Physics B: Lasers and Optics 67.4 (1998): 399-410.

[2] Hair, Johnathan W., et al. "Airborne high spectral resolution lidar for profiling aerosol optical properties." Applied optics 47.36 (2008): 6734-6752.

[3] Burton, S. P., et al. "Observations of the spectral dependence of linear particle depolarization ratio of aerosols using NASA Langley airborne High Spectral Resolution Lidar." Atmospheric Chemistry and Physics 15.23 (2015): 13453-13473. 